\title{
Technology Foresight Research of Industrial Robot Based on Patent Analysis
}

\author{
Xionghui Wen \\ School of Business Administration, South China University of Technology, Guangzhou, China \\ Email: 393317379@qq.com
}

How to cite this paper: Wen, X.H. (2019) Technology Foresight Research of Industrial Robot Based on Patent Analysis. Journal of Data Analysis and Information Processing, 7, 74-90.

https://doi.org/10.4236/jdaip.2019.72005

Received: April 12, 2019

Accepted: May 24, 2019

Published: May 27, 2019

Copyright (c) 2019 by author(s) and Scientific Research Publishing Inc. This work is licensed under the Creative Commons Attribution International License (CC BY 4.0).

http://creativecommons.org/licenses/by/4.0/

\begin{abstract}
In view of the lack of patent big data in research on technology foresight in the industrial robot field, this paper introduces an improved method based on patent mining and knowledge map. Firstly, SAO structure is extracted from selected patents, secondly, the similarity between patents is calculated based on extracted SAO structure, thirdly, patent network and patent map are drawn based on calculated patent similarity matrix, technology evolution process and future trends of industrial robot are summarized from patent network, and future potential technology opportunities are predicted based on technological vacancies identified from patent map. Finally, this paper identifies six key technical areas and four potential technical opportunities in the field of the industrial robot.
\end{abstract}

\section{Keywords}

Technology Foresight, Patent Mining, SAO, Knowledge Map, Industrial Robot

\section{Introduction}

In the 21st century, when the role of scientific and technological progress in the engine of economic development is becoming more and more obvious, science and technology competition between countries is intensifying, how to filter many technical fields and concentrate resources on areas of greatest potential for development, it's a matter of great concern to both enterprises and governments, technology foresight is an effective way to solve this problem. In addition, the inevitable nature of the application of technology makes it important to study the impact of new technologies in advance, so it is necessary to carry out technology foresight activities.

China has clearly defined its strategic transformation goal toward "Strong Manufacturing Country". At present, the target is still relatively broad and va- 
gue, and there is no in-depth technical analysis, especially the technology foresight of industrial robot. The manufacturing industry of China urgently needs to promote intelligent manufacturing and achieve upgrading. Through technology foresight, the development direction of industrial robot technology will be condensed; the industrial robot industry will be guided to achieve industrial innovation and technological progress, and key technologies that will lead the future to be identified for strategic focus and R\&D investment, which is important for improving the R\&D capability of smart equipment in China.

\section{Literature Review}

Technology foresight is a systematic process that identifies future technological developments and their interactions with the economy, society, as well as environment, and provides actionable guidance for creating a better future [1] [2]. The definition of technology foresight has not yet formed a unified opinion in academia, and the most representative one is the explanation given by Professor Ben Martin in 1995, he pointed out that technology foresight is a system to study the future situation of the economy, science, and technology, identify high-value research areas and select general-purpose new technologies that can produce the greatest economic and social effects, then point the research way for government and enterprise [1]. In addition, APEC has proposed a similar definition, which further highlights the environmental effects of strategic research and common new technologies based on Professor Martin's definition [2]. As the leading role of science and technology in social and economic development continues to increase, developed countries such as the United States and Japan have tried to apply technology foresight to the formulation of technology development, and gradually spread it around the world [3]. In 2014, Thomson Reuters used patent database search and existing scientific literature to analyze research trends, and released "Thomson Reuters Forecasts 20 Global Innovations in 2025", which points out that 10 fields including quantum transmission, bio-nano, solar energy, and digitalization that may make major breakthroughs in the future [4]. Russia's technology foresight activities originated in 1990 and in 2007 the Russian Ministry of Education and Science launched "2025 Science and Technology Development Foresight Project", which is divided into three main parts including industrial foresight, technology foresight and macroeconomic foresight [5]. The United States has drawn a robotic technology roadmap through technology foresight activities and pointed out key capabilities of industrial robots [6]. In Japan's ninth science and technology foresight report, it is predicted that autonomous robots with complex judgment will be developed by 2020 , and autonomous deep-sea subsurface excavation robot will be developed by 2023. China has carried out technology foresight work since 1992 [7]. In October 2015, the National manufacturing power construction strategy advisory committee issued a "Made in China 2025 technology roadmap for key areas", which points out that the key common technologies of industrial robot include whole ma- 
chine technology, component technology, integrated application technology, and key components include the reducer, controller, servo system, sensor [8]. In general, domestic scholars' research on industrial robot focuses on the macro-policy research, while the research on patents focuses on the impact of patent alliances on innovation [9]. There are few published literatures on the research of patent map of intelligent manufacturing equipment and industrial robot by foreign scholars, the reason may be to consider protecting the international competitive advantage and technical secrets, or the hollowing out of foreign manufacturing.

At present, technology foresight methods can be summarized as qualitative analysis based method, quantitative analysis based method, and multi-method combination method. Although quantitative analysis based method of technology foresight has developed a lot, the current method is still dominated by qualitative analysis and supplemented by quantitative analysis, with strong subjectivity, so more scientific and effective quantitative analysis based methods need to be developed to make up for the deficiency of qualitative analysis based methods. Brockhoff pointed out that patents contain $90 \%$ to $95 \%$ of all the world's latest scientific and technological knowledge [10]. Patent document details the background of an invention; these functions can be realized and specific implementation schemes, which is the best way to understand technology innovation trends. Therefore, patent analysis is an important tool for technology foresight.

Patent analysis refers to the processing of some patent information in patent literature by means of data processing or statistical analysis, so as to provide organizations with valuable information that can comprehensively understand and predict a certain field [11]. It can be seen from the definition that extracting value information is the essential feature of patent analysis, which can be divided into three processes: Searching patent literature to determine information source, extracting and processing original information, and mining value information to present to the audience. PM theory is the theoretical basis of patent analysis [12]. The two directions of patent analysis can be divided into value mining based on text attribute and statistical analysis based on digital attribute. The former is the research content of data mining while the latter is the research field of bibliometrics. Therefore, patent analysis can be regarded as a method system formed by the intersection of the two fields [13].

The statistical analysis based on digital attributes mainly analyzes the external digital features of patent documents, such as statistical analysis of patent number for applicants, application years, and applicant countries. Chen Xin et al. [14] analyzed the changing relationship of patent number and the changing relationship of quality score in the Pearl River Delta, pointed out that there was a situation of uncoordinated growth and put forward the patent quality improvement suggestion. Guo Ying et al. [15] used patent measurement method and analytical tools to analyze Chinese patents issued by the USPO, and analyzed the influence and research status of relevant fields in China to help Chinese enterprises realize 
transnational expansion. Zhang Huabao et al. [16] analyzed the patent data of SCUT, such as the distribution of inventors, patent distribution field and the trend of number changing with time. Citation analysis of patents is also an important way of technology foresight, the emergence of patent with high citation and high innovation level is an important symbol of the development process of high-tech industry [17]. Excel, TDA, Citespace and Network are common tools to analyze the external characteristics of patent documents.

A common shortcoming of statistical analysis based on numerical attributes is the loss of high-value unstructured patent document text information. Therefore, more and more researches begin to focus on the method of patent text mining to deeply explore the content of patent texts [18]. KWA (keyword-based analysis) is one of the representative methods, which calculates the distance between patents based on information such as the frequency of keyword occurrence in patent and the number of keyword occurrence simultaneously [19]. As a new method, the patent analysis method based on SAO (Subject-Action-Object) can obtain more semantic information than KWA [20]. Using patent network and patent map to reduce high-dimensional data to two-dimensional and showing the core patents in the network center can further analyze patent vacancies and technology hot spots, predict the development trend of high-tech [21], discovery potential technological opportunities [22], predict new technology concepts, and draw technology roadmap.

\section{Data Acquisition and Technical Status Analysis}

\subsection{Overview of Industrial Robot}

The International Organization for Standardization (ISO) defines industrial robot as three-axis or multi-axis multi-purpose manipulator oriented at automatic control and reprogrammable in the field of industrial automation [23]. With the development of technology, the definition of industrial robot is also changing constantly. The Japanese Industrial Standard (JIS) defines industrial robot as a machine with mobile or operational functions, using automatic control technology and realizing various operations through various software programs, which can be used in the industrial field [24].

According to the above definition, industrial robot refers to mechanical devices that can replace human labor through various automated operations in the industrial field, and is usually used in handling, welding, spraying and assembly, etc [25]. Early industrial robots replicated the mechanical principles of human arm one-to-one, with basic control capabilities and little ability to perceive the environment. In the middle and late 20th century, the development of integrated circuits, digital computers and miniaturized components enabled the realization of computer-controlled robots. In 1954, the world's first programmable industrial robot was born. Then in the late 1970s, industrial robots have become an important part of the flexible automation manufacturing system. After more than 60 years of development, industrial robots have been widely used in many industrial fields such as automotive, metal products, chemical, electronics and 
food industries. Industrial robot can free people from heavy monotonous and even high-risk industrial production activities, while also improving production efficiency and quality, and gradually become the core equipment and indispensable infrastructure in the tertiary industry. The industrial robot system is shown in Figure 1, its three core components include controller, servo motor and reducer. Controller belongs to control system and is the brain of the whole robot system, servo motor belongs to the driver in drive system, which is used to provide power to the actuator part, and reducer is the reduction transmission between the drive system and the execution system.

At present, the technical level and popularization scale of industrial robots in China are quite different from those of developed countries represented by Japan, the United States, Germany, and South Korea. Taking the density of robot as an example, Figure 2 shows that as of 2016, the density of industrial robot in China is only 68 units/10,000 people, which are still lower than the world average level, about $1 / 9$ of that of South Korea. In such a wide gap, we need to carry out industrial robot technology foresight relevant activities, and help the development of industrial robot technology.

\subsection{Patent Retrieval}

By reading these key technical literatures, the related patents were retrieved with industrial robot as the key word. Since it usually takes nearly two years to review a patent application before it is authorized, most of the patents will be rejected during this period. In order to improve the quality of the patent data, this paper

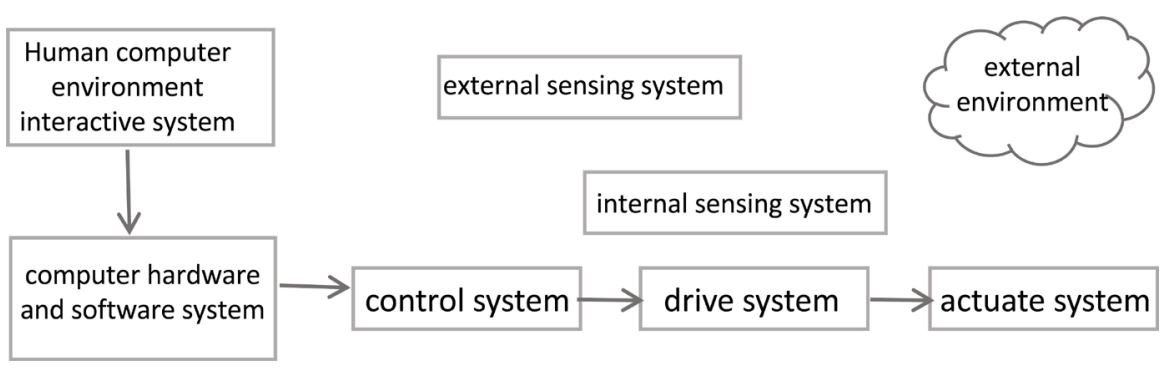

Figure 1. Industrial robot system.

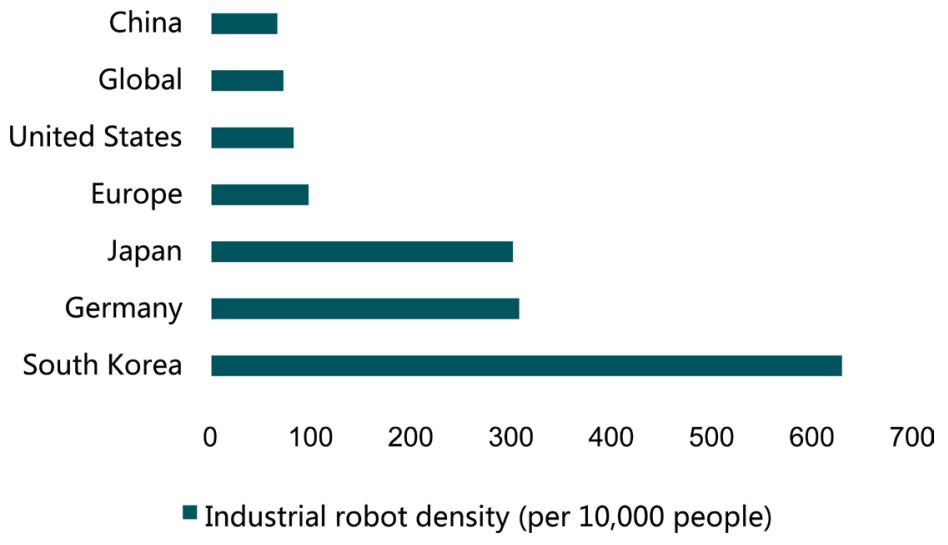

Figure 2. Industrial robot density around the world in 2016. 
only retrieves the authorized patents, and the patent retrieval type compiled is as follows: @(title,abstract, claims, body) (("industr" robot $\left.^{*} \sim 1\right)$ or ("industr* manipulat" 1$)$ ) @(title,abstract, claims) ("robot*"or"manipulat") @ @* (kind_code_b or kind_code_b1 or kind_code_b2 or kind_code_c or kind_code_y or kind_code_u) (@* inno_utility_patent), where “@(title, abstract, claims, body)" and “@(title, abstract, claims)" represent defined search scope, "(("industr" robot $\left.^{\star} \sim 1\right)$ or ("industr

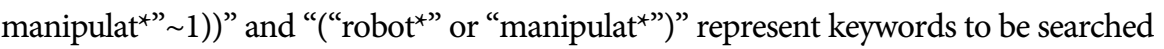
within the specified search scope, and "("industr* robot" $\sim 1)$ " represents fuzzy matching, and the rest of the suffixes are the screening of patent types.

By using the retrieval method above, a total of 18,100 pieces of authorized patent data were obtained on the patent analysis platform, and the data were downloaded to the local database as the basic data for subsequent analysis.

\subsection{Analysis of Technical Status}

\subsubsection{Development Stage Analysis}

By analyzing the application time of 18100 patent data, the number of patent applications in each year is shown in Figure 3. Since it usually takes 18 months from patent application to final authorization publication, patents of 2018 and 2019 are not reflected in Figure 3. It can be clearly seen from Figure 3 that in the 1950s, patents related to industrial robot began to appear and then slowly increased over time, from the 1980s to the late 1990s, patent applications showed a declining trend. In the $21^{\text {st }}$ century, the number of patent applications has entered a stage of rapid growth, presenting an explosive growth. According to the characteristics of quantity change, this paper divides the development process of industrial robot into the following three stages:

1) Concept presentation stage (1954-1987). In the 1930s, the concept of robot began to appear. And in 1954, American George Dvor applied for the world's

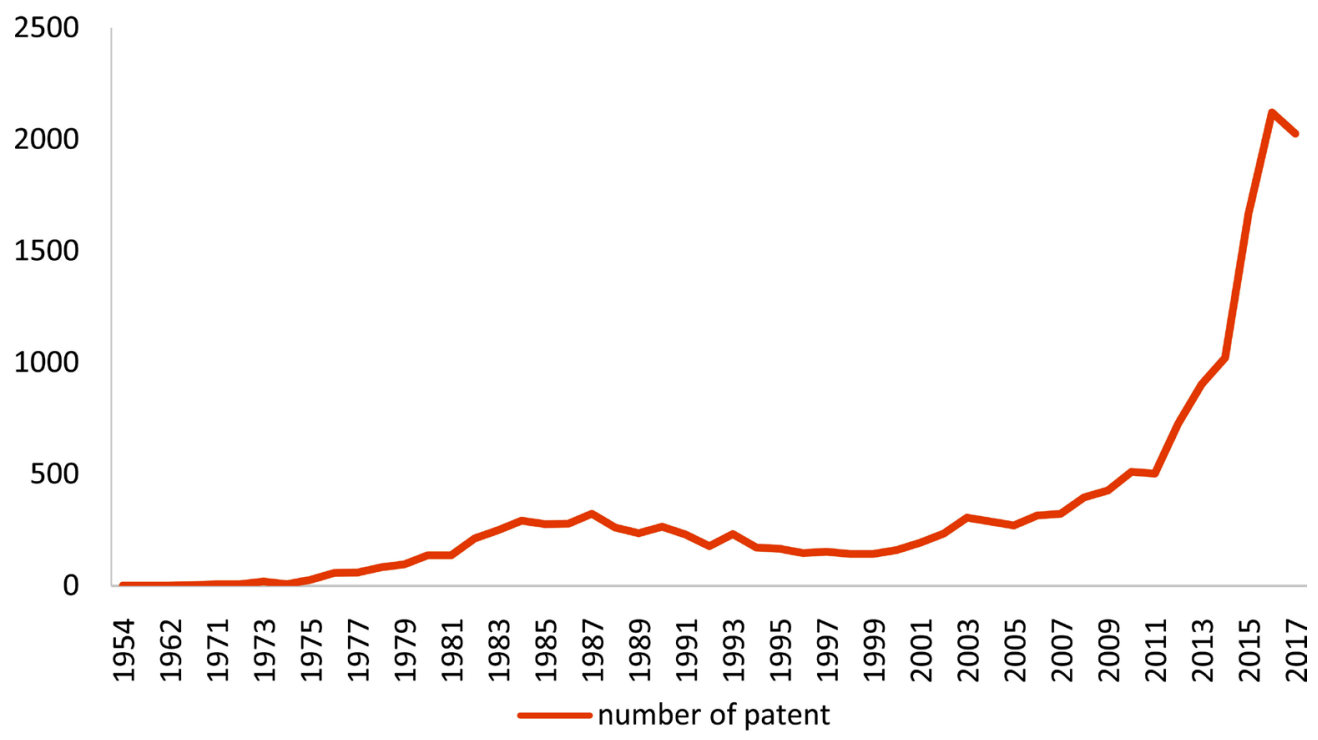

Figure 3. Number of patent applied for each year. 
first industrial robot patent "a programmed article transfer", providing a programmable joint transfer material device. This stage belongs to the germination period of technology and is also the popularization period of industrial robot related concepts, and the market scale is small. In the late 1970s, many companies from Europe, America, and Japan began the global deployment of industrial robot patents.

2) Extinction stage of upsurge (1987-2005). At this stage, the number of patents showed a trend of decline year by year. Main reasons for the decline were the lack of unified industry standards, the failure to break the barriers of cross-industry cooperation, the patent monopoly of important production technologies, and the dislocation between product value and public demand.

3) Rapid development stage (2006-present). This stage is marked and driven by breakthroughs in artificial intelligence, machine learning and other related technologies, as well as increased policy support for the development of industrial robot industry in various countries. For example, in the "Industrial Transformation and Upgrading Plan (2011-2015)", the Chinese government has identified the development direction of intelligent manufacturing equipment, including accelerating the development of industrial robots such as welding, handling, and assembly robot.

\subsubsection{Analysis of the Patentee}

The patentee here refers to the entity that currently enjoys the patent right, which can be citizens, collective ownership units, foreign trade enterprises, and sino-foreign joint ventures. A total of 5482 patents are identified from 18,100 patent data, as shown in Figure 4, of which 11035 patents are held by enterprises,

Figure 4. Distribution of patent owned by various types of patentees. 
3370 patents are held by schools and specialized research institutions, and 2583 patents are held by individuals, the patent holders of the remaining 288 patents are missing. The corporate sector holds more than half of the patents related to industrial robot, indicating the active commercialization of industrial robot.

Among all the patentees, the top 20 patent holders are listed in Table 1, including 18 companies and 2 research institutions. Among the 18 companies, 14 are Japanese, which has absolute advantages in terms of number. And the two institutions are the Fraunhofer-Gesellschaft in Germany and the Chinese Academy of Sciences. The "Four Major Families" of industrial robot are ranked in the top four respectively, which not only have an advantage in the number of patent, but also have a very large advantage in their products and services.

\section{Technology Foresight Analysis Based on SAO Method}

\subsection{Data Processing Based on SAO Method}

\subsubsection{SAO Structure Extraction}

In this paper, the patent strength algorithm of the Innography patent analysis platform is used to select patents with strength greater than 2, so the low-value patents are excluded. Finally, 7247 patent data are obtained and stored in a local database.

SAO structure can be automatically extracted from the text using existing natural language processing tools. Currently, there are three softwares for extracting SAO structure, including Knowledgist, AlchemyAPI and Stanford Parser. Stanford Parser is a syntactic parser developed by Stanford University that can recognize English, Chinese and Arabic and is a fully open source natural language processing tool. In this paper, Stanford Parser is adopted as SAO extraction tool, and the SAO structure is extracted by the software package offered by Java development environment IntelliJ IDEA. Before extracting SAO structure, original patent data should be cleaned firstly. Finally, 65,225 SAO are

Table 1. Number of patent ranking of top 20 patentees.

\begin{tabular}{cccc}
\hline Ranking & Organization & Ranking & Organization \\
\hline 1 & Fanuc Ltd. & 11 & Denso Corporation \\
2 & ABB Ltd & 12 & Seiko Epson Corporation \\
3 & Kuka AG & 13 & Toshiba Corporation \\
4 & YASKAWA Electric Corporation & 14 & Siemens AG \\
5 & Mitsubishi Electric Corporation & 15 & Fraunhofer \\
6 & Hitachi, Ltd. & 16 & Honda Motor Co., Ltd. \\
7 & Panasonic Corporation & 17 & Kobe Steel, Ltd. \\
8 & Samsung Electronics Co., Ltd. & 18 & Chinese Academy Of Sciences \\
9 & Kawasaki Heavy Industries, Ltd. & 19 & Toyota Motor Corporation \\
10 & Sony Corporation & 20 & Canon Inc. \\
\hline
\end{tabular}


extracted from 7247 patents, and finally a total of 62,738 SAO structures are obtained after cleaning.

\subsubsection{Patent Similarity Measurement}

This paper uses the Lin algorithm in JAVA's JWS open source project, combined with WordNet semantic dictionary, to calculate the similarity between vocabulary. Lin algorithm is the most widely used classical semantic similarity algorithm recently. The lexical similarity calculation is shown in Equation (4-1):

$$
\operatorname{Lin}\left(W_{1}, W_{2}\right)=\frac{2 * \operatorname{depth}\left(\operatorname{lcs}\left(W_{1}, W_{2}\right)\right)}{\operatorname{depth}\left(W_{1}\right)+\operatorname{depth}\left(W_{2}\right)}
$$

where, depth $\left(W_{i}\right)$ is the distance from the vocabulary $W_{i}$ node to its root concept node, $\operatorname{lcs}\left(W_{1}, W_{2}\right)$ represents the minimum common subset of vocabulary $W_{1}$ and $W_{2}$, and $\operatorname{Lin}\left(W_{1}, W_{2}\right)$ has the minimum value of 0 , indicating that the two terms are completely different, And the maximum value of 1 , indicating that the two terms are exactly the same.

Based on the similarity calculating method between words, Lin algorithm is adapted to calculate the similarity between two sentences, as shown in Equation $(4-2)$ :

$$
\operatorname{Sim}^{\prime}(X, Y)=\frac{2 * \operatorname{Match}(X, Y)}{|X|+|Y|}
$$

where, $\operatorname{Sim}^{\prime}(X, Y)$ represents the similarity of two sentences, and its value is 0 to 1 . The larger the value is, the higher the similarity between two sentences will be. $\operatorname{Match}(X, Y)$ represents the logarithm of the same feature in sentence $X$ and sentence $Y$, and 2 times represents the number of the same feature; $|X|$ and $|Y|$ represent the number of features in sentence $X$ and sentence $Y$ respectively.

SAO has a complete sentence structure, subject $S$ and object $O$ are mostly phrases composed of multiple words, representing products, technologies or technical indicators. Therefore, the similarity of each part of the SAO structure should be calculated separately, and then the comprehensive similarity can be obtained, as shown in Equation (4-3):

$$
\operatorname{Sim}^{\prime}\left(S A O_{i}, S A O_{j}\right)=\left[\operatorname{Sim}^{\prime}\left(S_{i}, S_{j}\right)+\operatorname{Sim}^{\prime}\left(A_{i}, A_{j}\right)+\operatorname{Sim}^{\prime}\left(O_{i}, O_{j}\right)\right]
$$

where, $\operatorname{Sim}^{\prime}\left(S_{i}, S_{j}\right), \operatorname{Sim}^{\prime}\left(A_{i}, A_{j}\right)$ and $\operatorname{Sim}^{\prime}\left(O_{i}, O_{j}\right)$ respectively refer to the similarity of $\mathrm{S}, \mathrm{A}$ and $\mathrm{O}$ combination in $S A O_{i}$ and $S A O_{j}$. When the value reaches a certain threshold value $t$, it is deemed that $S A O_{i}$ and $S A O_{j}$ are completely the same; otherwise, they are considered different. The judgment formula is shown in Formula (4-4):

$$
S O_{i j}=\left\{\begin{array}{l}
1, \operatorname{Sim}\left(S O_{i}, S O_{j}\right) \geq t \\
0, \text { other }
\end{array}\right.
$$

Then, the similarity between patent $A$ and patent $B$ can be calculated, as shown in Equations (4)-(5): 


$$
\operatorname{Sim}_{A, B}=\frac{2 * \operatorname{Match}(A, B)}{|A|+|B|}
$$

where, $\operatorname{Sim}(A, B)$ is the patent similarity, the higher the value is, the higher the similarity is. When the value is 1 , it means that the two patents are identical. $|A|$ and $|B|$ represent the number of SAO in patent $A$ and $B$ respectively, and $\operatorname{Match}(A, B)$ represents the logarithm of the same SAO in patent $A$ and $B$.

According to the above method, the similarity between patents is calculated based on the extracted SAO structure, then the patent similarity matrix is obtained, as shown in Table 2.

\subsection{Patent Network Analysis}

This paper uses the Ucinet analysis tool to draw a patent network for the industrial robot patent data. In order to facilitate the identification of the core patents, the display threshold $t$ of the edge is set here, and the edge below the threshold $t$ will not be shown in the patent network, besides, isolated points will not appear in the network also.

From Figure 5, the core patents in the field of industrial robots can be clearly identified, and these core patents are carefully studied, classified according to their technical themes. The larger the circle in Figure 5, the more patents is associated with it. It should be noted that the color in the figure is independent of the size of the graphic, just to more clearly show the size and location of each patent.

Table 2. Patent similarity matrix (partial).

\begin{tabular}{|c|c|c|c|c|c|c|c|c|c|c|c|c|c|c|c|}
\hline & P1 & P2 & P3 & P4 & P5 & P6 & P7 & P8 & P9 & P10 & P11 & P12 & P13 & P14 & P15 \\
\hline P1 & 0.000 & 0.493 & 0.404 & 0.400 & 0.368 & 0.458 & 0.391 & 0.333 & 0.396 & 0.430 & 0.435 & 0.369 & 0.395 & 0.409 & 0.482 \\
\hline $\mathrm{P} 2$ & & 0.000 & 0.532 & 0.412 & 0.398 & 0.485 & 0.440 & 0.446 & 0.511 & 0.483 & 0.483 & 0.452 & 0.339 & 0.554 & 0.481 \\
\hline P3 & & & 0.000 & 0.424 & 0.446 & 0.469 & 0.372 & 0.352 & 0.502 & 0.450 & 0.391 & 0.452 & 0.459 & 0.516 & 0.505 \\
\hline P4 & & & & 0.000 & 0.393 & 0.383 & 0.367 & 0.369 & 0.391 & 0.378 & 0.407 & 0.406 & 0.357 & 0.405 & 0.414 \\
\hline P5 & & & & & 0.000 & 0.407 & 0.373 & 0.359 & 0.431 & 0.388 & 0.387 & 0.446 & 0.275 & 0.451 & 0.451 \\
\hline P6 & & & & & & 0.000 & 0.400 & 0.357 & 0.522 & 0.452 & 0.423 & 0.428 & 0.226 & 0.490 & 0.396 \\
\hline P7 & & & & & & & 0.000 & 0.402 & 0.400 & 0.392 & 0.348 & 0.370 & 0.361 & 0.399 & 0.404 \\
\hline P8 & & & & & & & & 0.000 & 0.329 & 0.389 & 0.305 & 0.285 & 0.316 & 0.335 & 0.361 \\
\hline P9 & & & & & & & & & 0.000 & 0.359 & 0.415 & 0.410 & 0.384 & 0.382 & 0.501 \\
\hline P10 & & & & & & & & & & 0.000 & 0.435 & 0.403 & 0.401 & 0.466 & 0.457 \\
\hline P11 & & & & & & & & & & & 0.000 & 0.344 & 0.397 & 0.431 & 0.395 \\
\hline P12 & & & & & & & & & & & & 0.000 & 0.404 & 0.479 & 0.423 \\
\hline P13 & & & & & & & & & & & & & 0.000 & 0.426 & 0.307 \\
\hline P14 & & & & & & & & & & & & & & 0.000 & 0.476 \\
\hline P15 & & & & & & & & & & & & & & & 0.000 \\
\hline
\end{tabular}




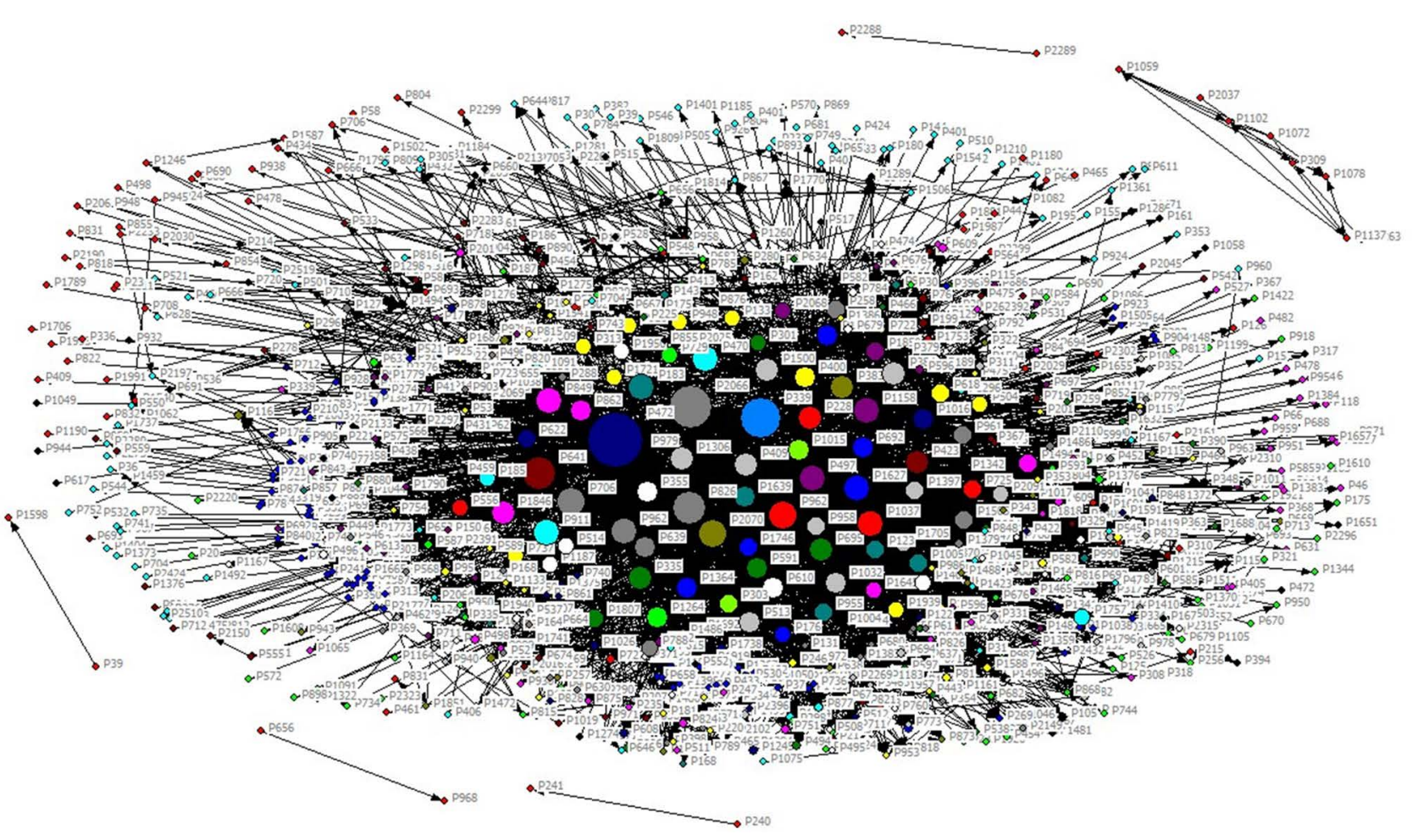

Figure 5. patent network (1954-present).

According to Table 3, the core technologies in the field of industrial robots include sensing technology, network communication technology, control technology, programming technology, interactive technology, and mobile technology.

In terms of sensing technology, the types of sensors are constantly enriched, and the sensing systems of robots are becoming more and more complex. From the initial force, position and speed sensors to the current proximity sensing, machine vision and other intelligent sensing technologies, industrial robot of awareness are becoming more and more close to human limits even greater than that of human perception.

In terms of network communication, early wired communication technologies gradually developed wireless communication technologies including WIFI, Zigbee, and Bluetooth suitable for different occasions. From wireless communication to wired communication, the efficiency of information transmission is higher and the energy consumption is lower, and the scope of communication has been greatly expanded.

In terms of control technology, the early stage of program control is mainly based on teaching reproduction control technology. With the continuous development of sensing technology, the adaptive control method with feedback function can be realized, making industrial robots have stronger environmental adaptability; therefore, the application scenario is broadened. At present, intelligent control represented by fuzzy control, optimal control, neural network control is the current research hot spot.

In terms of programming technology, the fixed program generated by the 
Table 3. Core patents analysis.

\begin{tabular}{|c|c|c|}
\hline Core Patent Number & Key SAO & Technology Theme \\
\hline $\begin{array}{l}\text { P1816 } \\
\text { P4976 } \\
\text { P1264 } \\
\text { P1364 } \\
\text { P335 } \\
\text { P24 }\end{array}$ & $\begin{array}{l}\text { [Position sensor-produce-output signal]; } \\
\text { [Vision unit-photograph-guide line]; } \\
\text { [Safety sensor-comprise-contact-free proximity sensor]; } \\
\text { [Pair of camera-obtain-camera image coordinate system]; } \\
\text { [Industrial grinding robot-have-visual sense and touch sense]; } \\
\text { [Proximity sensor-detect-safety-relevant part of working chamber]; } \\
\text { [Pair of camera-obtain-camera image coordinate system]; } \\
\text { [Sensor model simulate sensor imaging]. }\end{array}$ & Sensing Technology \\
\hline $\begin{array}{l}\text { P639 } \\
\text { P4264 } \\
\text { P849 } \\
\text { P862 } \\
\text { P1306 }\end{array}$ & $\begin{array}{l}\text { [Master controller and intelligent terminal-be in wireless communication } \\
\text { connection with-cloud server]; } \\
\text { [Receiver-receive-wireless information]; } \\
\text { [System comprise ZIGBEE local area network module]; } \\
\text { [Robot body include Bluetooth module information store unit]; } \\
\text { [Automatic charge grind equipment comprise RFID label array]. }\end{array}$ & $\begin{array}{c}\text { Network } \\
\text { Communication } \\
\text { Technology }\end{array}$ \\
\hline $\begin{array}{l}\text { P826 } \\
\text { P962 } \\
\text { P591 } \\
\text { P1639 } \\
\text { P3548 } \\
\text { P641 } \\
\text { P1705 } \\
\text { P123 }\end{array}$ & $\begin{array}{l}\text { [Controller-recognize-position by image]; } \\
\text { [Control device-monitor-state of photosensor]; } \\
\text { [Cloud control mode improve communication efficiency]; } \\
\text { [Fuzzy controller-control-automatic guiding vehicle]; } \\
\text { [Invention-disclose-trajectory tracking control method]; } \\
\text { [System-comprise-numerical control subsystem]; } \\
\text { [Position and speed data on teaching point-be supply to-arithmetic controller]; } \\
\text { [Invention-disclose-multifunctional screw tighten system and control method]; } \\
\text { [Regular patterning code locating controller-control-tray label reading code]. }\end{array}$ & $\begin{array}{l}\text { The Control } \\
\text { Technology }\end{array}$ \\
\hline $\begin{array}{l}\text { P409 } \\
\text { P2066 } \\
\text { P1721 } \\
\text { P2025 } \\
\text { P1500 } \\
\text { P1394 }\end{array}$ & $\begin{array}{l}\text { [Position and speed data on teaching point-be supply to-arithmetic controller]; } \\
\text { [Teaching-produce-new control information]; } \\
\text { [Path programming technology-design-cleaning path]; } \\
\text { [Invention provide complex path programming method]; } \\
\text { [Invention discloses offline programming and modifying method]. }\end{array}$ & $\begin{array}{l}\text { Programming } \\
\text { Technology }\end{array}$ \\
\hline $\begin{array}{c}\text { P5011 } \\
\text { P962 } \\
\text { P706 } \\
\text { P3217 } \\
\text { P4531 }\end{array}$ & $\begin{array}{l}\text { [Handheld teaching unit comprise interface]; } \\
\text { [Operation adopt human-computer interface]; } \\
\text { [AGV trolley is connected with PC through PLC and wireless WiFi]; } \\
\text { [Graphic editing interface is used for interactive graphic programming between user and system]. }\end{array}$ & Interactive Technology \\
\hline $\begin{array}{l}\text { P1257 } \\
\text { P5010 } \\
\text { P911 } \\
\text { P3976 }\end{array}$ & $\begin{array}{l}\text { [Intelligent moving and cleaning robot-be used in -large scale cleaning equipment]; } \\
\text { [Automatic guided system-include-automatic guided vehicle]; } \\
\text { [Invention-provide-mobile robot]; } \\
\text { [Welding main body-slide on-guide rail device]. }\end{array}$ & Mobile Technology \\
\hline
\end{tabular}

traditional online teaching programming technology has poor adaptability to the actual situation and needs to occupy the working time of the robot, so it is gradually replaced by offline programming and semi-automatic programming technol- 
ogy. Semi-automated programming can reduce manual intervention and increase the automation and intelligence level, and will move toward self-programming in the future, which is also the key technology to realize intelligent technology.

In terms of interactive technology, from the early teaching box to the current intelligent terminal, the interactive devices are more and more diverse, and the way of interaction is more and more humanized. In the future development, human-computer interaction will further develop in a user-friendly direction, such as further development of intelligent interaction technology that controls robots through gestures, language and expressions.

In terms of mobile technology, from the beginning of the rail movement to the current industrial drones, the mobility of industrial robots is getting stronger and stronger, the range of movement is getting larger and larger, and the number of movable paths is increasing. With the development of mobile technology, the energy consumption of devices and the security between devices will become more and more prominent.

\subsection{Patent Map Analysis}

The patent map of industrial robot is shown in Figure 6. By carefully studying the technical vacancies on the patent map, potential technical opportunities are explored and four valuable technical vacancies are identified. Carefully study patents around technical vacancies, and analyze its core SAO structure and major technical topics, to interpret potential technology opportunities finally.

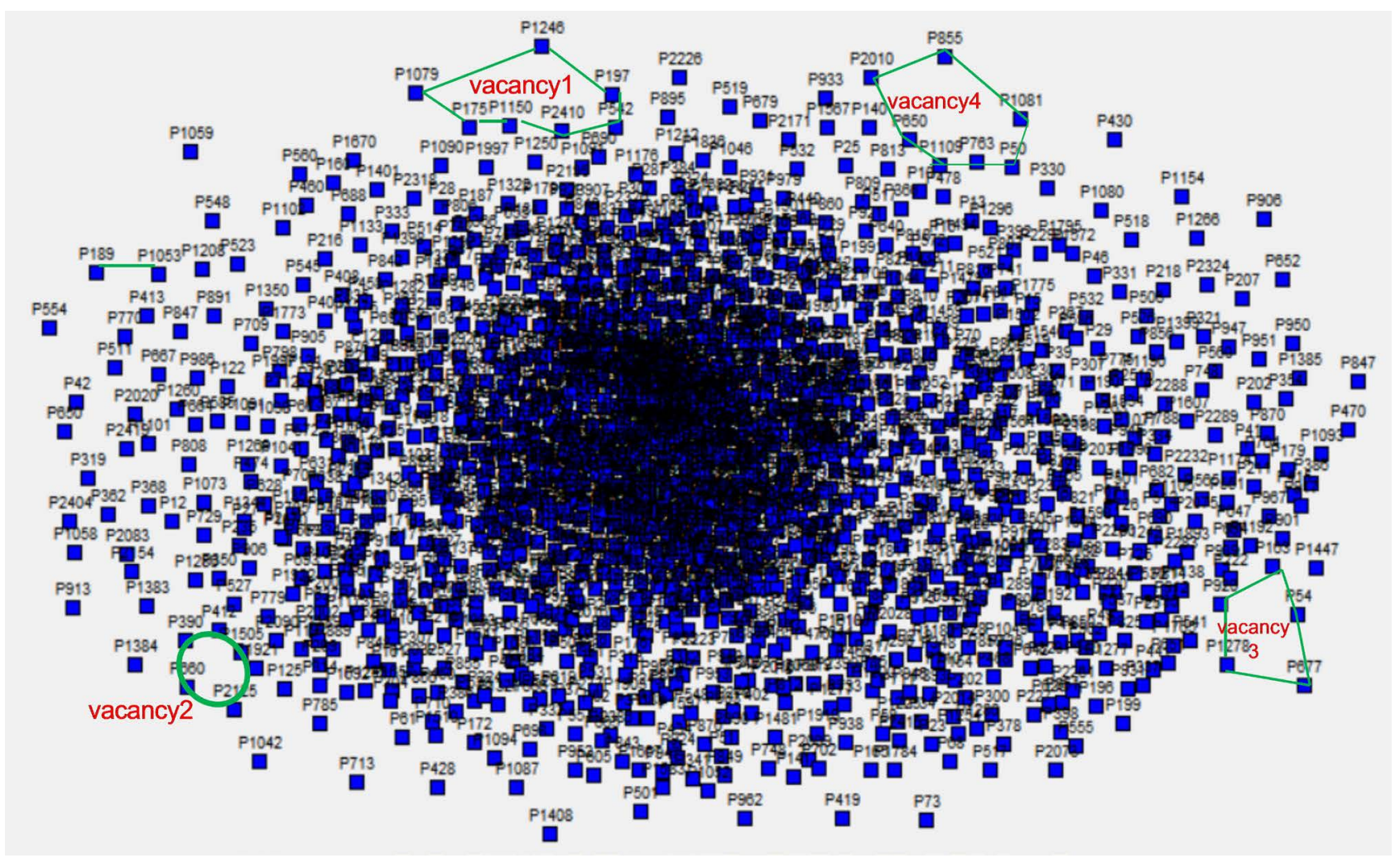

Figure 6. Patent map. 
Vacancy 1: Intelligent Sensing System. Most of the patents around Vacancy 1 involve sensing and measurement-related technologies to improve the accuracy of data acquisition and achieve sensor integration. Robots can't be isolated; it must be integrated with the environment to work properly. The idea of IoT is to create an organism that interconnects machines, environment and people together.

Vacancy 2: Generalization, Standardization, Networking. The development trend of the future robot technology is generalization, standardization and networking. On the one hand, it can facilitate the robot information interaction between different manufacturers, realizes long-distance operation monitoring, maintenance and remote control. On the other hand, it can also reduce the industry cost. Modular and flexible robot has strong adaptability to the environment and task, and its cost advantage is obvious, which will lead the development of high-tech manufacturing in the future.

Vacancy 3: Reducing energy consumption and developing green technology. The patents around vacancy 3 are mainly related to the technology of power supply for industrial robot system. At present, wireless power supply (P489-JP6076426, Automatic guided vehicle and power supply system) has emerged. If the technology can further reduce the drive and servo motor energy consumption, it is bound to bring new development opportunities. In addition, it can also be combined with solar energy and other new clean energy to power equipment, in line with the environmental protection-oriented technology development ideas in 21st century.

Vacancy 4: Remote Management and Control. The technical subject described in patents around vacancy 4 is mainly related to remote monitoring, remote diagnosis, and remote control operation. Remote management and control can achieve physical isolation between workers and industrial work site and provide higher security. In addition, the development of remote control technology has made it possible to conduct industrial activities in all kinds of harsh environments, such as deep-sea mining operations, mineral exploitation and so on.

\subsection{Policies and Suggestions}

\subsubsection{Establishing Patent Strategic Alliance}

A number of representative industrial robot companies have emerged in China, but their output value is low and cannot compare with the industrial robot multinational companies represented by the "four major families" in terms of technology, scale and R\&D investment. Therefore, an effective way for domestic companies to compete with multinational companies is to adopt a patent strategic alliance to compete with multinational companies with the power of groups and alliances.

\subsubsection{Establishing Patent Warning Information Platform}

It is an important measure to make full use of big data analysis technology and timely grasp the development trend of industrial robot technology in the world to avoid the patent trap of industrial robot power. Through the analysis of big 
data from the three aspects of patent, market and law, the author gives an early warning on the threat situation of industrial robot patent, the development trend of key parts and technologies of industrial robot, the dynamics of main competitors and possible patent infringement disputes.

\subsubsection{Seeking Breakthrough in Key Segments}

The robot application in the automobile industry has been occupied by foreign robot giants, which is related to the early development of the automobile industry in developed countries. In China, new industries such as high-speed railway and new energy are the most competitive fields for Chinese robots. China has accelerated the application of automation in $3 \mathrm{C}$, ceramics, household appliances, logistics and other emerging fields, bringing more opportunities to robot enterprises. A comprehensive opportunity is to develop specialized industrial robots for the needs of niche segmentation.

\subsubsection{Improving Policy Support for Industrial Robot Industry}

Industrial robots have become the strategic commanding heights of the world in high-tech competition and are listed as a priority technology. Although China has included industrial robots in the strategic emerging industry catalogue and one of the 100 major projects and projects planned to be implemented during the 13th Five-Year Plan period in China, compared with Japan, Korea, and other countries, the industrial policy support system is still incomplete. Government should increase support and improve the industrial robot industry development policy.

\section{Conclusion}

Based on patent mining and knowledge mapping methods, this paper conducts a technology foresight study on the technological development in the field of industrial robot. In the aspect of text information extraction, the natural language processing open source library is comprehensively used, and the patent similarity calculation method based on SAO is proposed. Finally, with the help of patent network and patent map visualization tools, six key technical fields and four potential technical opportunities for industrial robot are summarized, and suggestions for the development of industrial robot in China are put forward finally.

\section{Conflicts of Interest}

The authors declare no conflicts of interest regarding the publication of this paper.

\section{References}

[1] Miles, I. (2010) The Development of Technology Foresight: A Review. Technological Forecasting and Social Change, 77, 1448-1456.

https://doi.org/10.1016/j.techfore.2010.07.016 
[2] Forecast, J. (2003) Technology Foresight-Past and Future. Journal of Forecast, 22, 79-82. https://doi.org/10.1002/for.846

[3] Gao, H., Wang, D. and Li, Z. (2018) A Review of the Theory and Practice of Technology Foresight. China Management Informationization, 21, 78-82.

[4] Reuters, T. (2016) The World in 2025: 10 Predictions of Innovation. http://sciencewatch.com/sites/sw/files/m/pdf/World-2025.pdf

[5] Sokolov, A., Chlok, A. and Mesropyan, V. (2013) Long-Term Science and Technology Policy-Russian Priorities for 2030. Social Science Electronic Publishing, New York. https://doi.org/10.2139/ssrn.2338040

[6] Yang, C. and Wei, H. (2017) Comparative Study on the Text Evaluation of Robotics Technology Roadmap among US, EU, Japan and China. Science of Science and Management of S. \& T., 38, 24-34.

[7] National Manufacturing Strategy Advisory Committee (2015) Made in China 2025 Technology Roadmap for Key Areas (2015 Edition).

[8] Ministry of Industry and Information Technology (2017) Industry Key Common Technology Development Guide. http://www.miit.gov.cn/n1146290/n4388791/c5884747/content.html

[9] Chen, Y., Tan, J., Wang, Z., et al. (2018) Technological Opportunity Analysis of Industrial Robots from the Perspective of Patents. Science Research Management, 39, 144-156.

[10] Brock-hoff, K.K. (1992) Instruments for Patent Data Analyses in Business Firms. Technovation, 12, 41-59. https://doi.org/10.1016/0166-4972(92)90031-C

[11] Ma, T. (2015) Patent Analysis: Methods, Chart Interpretation and Intelligence Mining. Intellectual Property Press, Beijing, 1.

[12] Zhao, Y., Dong, Y. and Zhu, X. (2006) Patent Analysis and Its Application in Intelligence Research. Library and Intelligence Work, 5, 19-22.

[13] Liu, Y. and Li, D. (2018) Patent Analysis Research Review and Application Suggestions for Scientific and Technological Intelligence. Science and Technology Management Research, 38, 155-160.

[14] Chen, X. (2017) Research on the Status Quo of Patent Strength in Nine Cities in the Pearl River Delta and Countermeasures to Improve It. Technology Management Research, No. 23, 186-191.

[15] Guo, Y., Qian, Y., Zhang, L., et al. (2017) Analysis of China's Technological Innovation Situation Based on Overseas Patent Layout. Technology Management Research, No. 23, 174-180.

[16] Zhang, H., Long, X. and Hu, J. (2010) Bibliometric Analysis of Domestic Patent Disclosure and Authorization in South China University of Technology. Intelligence Exploration, No. 12, 37-39.

[17] Liu, X., Wen, T. and Yang, Z. (2015) Patent Information Visualization Analysis System Status and Technical Basis. Information Theory and Practice, 38, 1-5.

[18] Li, X., Xie, Q., Huang, L., et al. (2018) Research on the Evolution Trajectory of Emerging Technologies Based on SAO Structural Semantic Mining. Science of Science and Management of Science and Technology, 39, 17-31.

[19] Chen, A., Liu, X. and Gao, G. (2012) Characteristics of the Formation of Highly Cited Patents in Emerging Industries-A Case Study of Fuel Cells. Scientific Research Management, 33, 9-15. https://doi.org/10.1016/S1464-2859(12)70274-2

[20] Jeong, C. and Kim, K. (2014) Creating Patents on the New Technology Using 
Analogy-Based Patent Mining. Expert Systems with Applications, 41, 3605-3614. https://doi.org/10.1016/j.eswa.2013.11.045

[21] Lee, C., Kang, B. and Shin, J. (2014) Novelty-Focused Patent Mapping for Technology Opportunity Analysis. Technological Forecasting and Social Change, 45, 3865-3876.

[22] Yoon, J. and Kim, K. (2012) An Analysis of Property-Function Based Patent Networks for Strategic R\&D Planning in Fast-Moving Industries: The Case of Silicon-Based Thin Film Solar Cells. Expert Systems with Applications, 39, 7709-7717. https://doi.org/10.1016/j.eswa.2012.01.035

[23] International Federation of Robotics (2017) Industrial Robots-Definition and Types WR 2016. https://ifr.org/img/office/Industrial Robots 2016 Chapter 1 2.pdf

[24] Li, F. (2017) Research on Enterprise Technology Innovation Capability Based on Patent Map. Liaoning University, Liaoning.

[25] Editorial Department of Robotics and Applications (2013) Current Situation and Development of Industrial Robots in China. Robotics and Applications, 1, 3-5. 